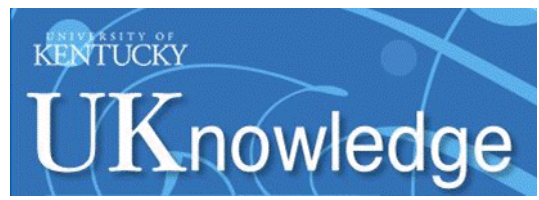

University of Kentucky

UKnowledge

Biosystems and Agricultural Engineering

Faculty Publications

Biosystems and Agricultural Engineering

2017

\title{
Evaluating a New Shade for Feedlot Cattle Performance and Heat Stress
}

\author{
Morgan D. Hayes \\ University of Kentucky, hayesmorgan@uky.edu \\ Tami M. Brown-Brandl \\ USDA Agricultural Research Service \\ Roger A. Eigenberg \\ USDA Agricultural Research Service \\ Larry A. Kuehn \\ USDA Agricultural Research Service \\ R. Mark Thallman \\ USDA Agricultural Research Service
}

Follow this and additional works at: https://uknowledge.uky.edu/bae_facpub

Part of the Animal Sciences Commons, and the Bioresource and Agricultural Engineering Commons

Right click to open a feedback form in a new tab to let us know how this document benefits you.

\section{Repository Citation}

Hayes, Morgan D.; Brown-Brandl, Tami M.; Eigenberg, Roger A.; Kuehn, Larry A.; and Thallman, R. Mark, "Evaluating a New Shade for Feedlot Cattle Performance and Heat Stress" (2017). Biosystems and Agricultural Engineering Faculty Publications. 216.

https://uknowledge.uky.edu/bae_facpub/216

This Article is brought to you for free and open access by the Biosystems and Agricultural Engineering at UKnowledge. It has been accepted for inclusion in Biosystems and Agricultural Engineering Faculty Publications by an authorized administrator of UKnowledge. For more information, please contact UKnowledge@lsv.uky.edu. 
Evaluating a New Shade for Feedlot Cattle Performance and Heat Stress

Digital Object Identifier (DOI)

https://doi.org/10.13031/trans.12104

Notes/Citation Information

Published in Transactions of the ASABE, v. 60, issue 4, p. 1301-1311.

The copyright holder has granted the permission for posting the article here.

This article is available at UKnowledge: https://uknowledge.uky.edu/bae_facpub/216 


\title{
Evaluating A New SHADE FOR FEEDlot CATTLE PERFORMANCE AND HEAT STRESS
}

\author{
M. D. Hayes, T. M. Brown-Brandl, R. A. Eigenberg, L. A. Kuehn, R. M. Thallman
}

\begin{abstract}
Heat stress in cattle results in decreased feed intake, lower daily gain, and potentially death in susceptible animals under intense conditions. A study was carried out during the summer of 2013 at the USDA-ARS U.S. Meat Animal Research Center feedlot evaluating the impact of shade on environmental conditions and cattle performance. A novel twotiered shade was used in half of the 14 pens, each holding 30 animals. The shades were designed to reduce solar heat load by $40 \%$ to $60 \%$ and to provide traveling shade across the pen, providing varied amounts of shade area as well as varied solar reduction potential. The objective of this study was to determine if the shade was effective at improving performance (evaluated as average daily gain, feed intake, and feed to gain ratio) and reducing environmental conditions that cause heat stress. A group of mixed-breed cattle with varied genetics including both Bos taurus and Bos indicus were selected, penned on the basis of sex, and blocked by color. Production parameters of pen feed usage were measured daily, and individual body weights were taken monthly. Environmental conditions including air temperature, relative humidity, wind speed, ground temperature, and black globe temperature with and without shade were measured. Solar load on the pens was reduced when shade was provided, with both ground temperature and black globe temperature showing reductions. Cattle showed nominally better performance; however, no significant differences were found in gain or feed intake. Panting scores were significantly lower with shade provided; slopes of cattle respiration rate versus ambient temperature were significantly lower with shade during the afternoon period.
\end{abstract}

Keywords. Cattle, Feedlot, Heat stress, Respiration, Shade.

$\mathrm{H}$ eat stress is a significant issue in U.S. feedlots and has major economic implications for the cattle industry. It is a concern for the cattle's health and well-being. Heat stress occurs when an animal gains more heat load through metabolic processes and environmental conditions than it can dissipate. Either prolonged (three or more days) high temperatures with similarly high nighttime temperatures or quick increases in air temperature can cause heat stress. However, air temperature alone does not produce heat stress. Other environmental conditions that increase the risk for heat stress include high humidity, high solar load, and low wind speeds.

Some common indices account for some of these environmental factors. Variations in a temperature humidity index (THI) are often used to describe environmental condition using the factors of temperature and relative humidity

Submitted for review in September 2016 as manuscript number PAFS 12104; approved for publication by the Plant, Animal, \& Facility Systems Community of ASABE in March 2017.

Mention of company or trade names is for description only and does not imply endorsement by the USDA. The USDA is an equal opportunity provider and employer.

The authors are Morgan D. Hayes, ASABE Member, Extension Assistant Professor, Department of Biosystems and Agricultural Engineering, University of Kentucky, Lexington Kentucky; Tami M. Brown-Brandl, ASABE Member, Research Engineer, Roger A. Eigenberg, Research Engineer, Larry A. Kuehn, Research Geneticist, and R. Mark Thallman, Research Geneticist, USDA-ARS Meat Animal Research Center, Clay Center, Nebraska. Corresponding author: Morgan Hayes, 212 C.E. Barnhart Building, University of Kentucky, Lexington, KY 40546; phone: 859-218-4350; e-mail: hayesmorgan@gmail.com.
(Mader et al., 2006; Gebremedhin et al., 2008). Gaughan et al. (2008) developed a heat load index (HLI), which included environmental factors of black globe temperature, relative humidity, and wind speed. This index in combination with an accumulated heat load (AHL) was used to provide risk assessment over time. Eigenberg et al. (2010) developed a respiration rate prediction model for cattle, which included environmental factors of temperature, relative humidity, wind speed, and solar radiation.

Within a group of cattle, the same environmental conditions can account for varying levels of heat stress and varying responses to the heat event. These responses include physiological and behavioral changes as well as increased risk of morbidity and possible mortality (Hahn and Mader, 1997; Gaughan et al., 2000; Mitlöhner et al., 2001). Respiration rate increases are a physiological response to increase evaporative cooling. Both feed intake and respective growth rates decrease during heat stress. The cattle decrease their feed intake as a physiologic response to lower their metabolic heat production. Studies have shown that cattle seek shade and adjust their body postures to mitigate heat stress (Robertshaw, 1985; Hillman et al., 2005; Mader et al., 2006).

Shade structures have the potential to help mitigate heat stress. These structures assist in reducing the stress by reducing the solar load on the animals and potentially the ground. Many studies have considered the potential benefits of shade structures (Parker, 1963; Bond et al., 1967; Blackshaw and Blackshaw, 1994; Mitlöhner et al., 2002; Eigenberg et al., 2010; Brown-Brandl et al., 2013; Sullivan et al., 2011). Many shade materials have been evaluated. Eigenberg et al. 
(2010) described the advantages of using snow fence as a shade material due to its durability and shade potential. Eigenberg et al. (2013) described a novel shade structure using snow fence installed and evaluated at the USDA-ARS U.S. Meat Animal Research Center (USMARC) feedlot. The design constraints were to "limit interference with pen operation, reduce heat stress, install at relatively low cost, limit maintenance demands, project dynamic shade area to reduce wet spots in pens, and tolerate Midwest snow and wind loads." These design constraints were effectively met by using a two-tier design that reduced solar load at the critical solar-noon period. The choice of snow fence as the shade material reduced the requirements for structural support, as the wind and snow load constraints were less stringent than with a solid shade material. The configuration was oriented north-south to provide a projected shade that traversed the pen as the solar azimuth and altitude changed throughout the day. This provided a dynamic shade that discourages cattle from loafing in one spot, with associated wet areas.

The overall objective of this study was to evaluate the differences between shaded and non-shaded pens with regard to environmental conditions, cattle performance, and heat stress. The specific objectives of this study were to evaluate differences in cattle performance, respiration rates, and environment within the pen based on shade availability over the final six weeks of finishing during summer conditions (early June through mid-July 2013).

\section{Method AND MATERIALS \\ SHADE DESIGN}

The shade structure used in this study is located at the USMARC feedlot $\left(40^{\circ} 33^{\prime} 14.90^{\prime \prime} \mathrm{N} ; 98^{\circ} 9^{\prime} 58.83^{\prime \prime} \mathrm{W}\right)$ and is situated on the north-south $(\mathrm{N}-\mathrm{S})$ fence line between pens. There are two major benefits of this placement. First, having the shade structure situated on the fence line reduces or eliminates interference with management of the pens. By placing the lowest shade tier approximately $4.5 \mathrm{~m}$ above the pen, even larger equipment can operate, such as the front-end loader used to clean out the pens. The second benefit is that the N-S orientation creates shadows that cover the width of the pen (east-west, E-W) as the sun tracks across the sky throughout the day. This provides a moving shaded area, which encourages the cattle to move as the shaded area tracks across the pen. This movement reduces wet areas due to congregation.

The shade structure includes two tiers of snow fence mounted $3 \mathrm{~m}$ apart. The snow fence material provides $30 \%$ reduction in solar load; with the two-tiered shade structure, the solar load can be reduced by more than $50 \%$ during peak solar hours, when the sun is directly overhead (Eigenberg et al., 2013). The support towers designed and implemented at the USMARC feedlot consist of two crossbeams $(3.4 \mathrm{~m}$ long, $0.073 \mathrm{~m}$ diameter) that are welded to a $10 \mathrm{~m}$ long steel pipe $(0.219 \mathrm{~m}$ diameter, $4.7 \mathrm{~mm}$ wall thickness $)$, with one crossbeam near the top and the second $3 \mathrm{~m}$ lower. These support towers are placed $7.6 \mathrm{~m}$ apart, with three towers per fence line, and set in concrete to a depth of $2.3 \mathrm{~m}$. Eight sets of three towers are installed in adjacent pens (pen numbers
125 to 133). Each pen is designed to hold 30 head of feedlot cattle. Figure 1 shows the installation of the support towers.

The snow fence material used in this design is a made of LLDPE resin (Product No. SF50-60100, Discount Fence Supply, Streetsboro, Ohio; $1.5 \mathrm{~m}$ wide, UV-resistant, fully stabilized, $55 \%$ opening, $23.6 \mathrm{~kg}$ per $30.5 \mathrm{~m}$ roll, temperature range of $-46^{\circ} \mathrm{C}$ to $82^{\circ} \mathrm{C}$ ). Each $15.2 \mathrm{~m}$ section of snow fence is supported by five wire rope cables $(6.35 \mathrm{~mm} 7 / 19)$ strung between the support crossbeams and held tight by threaded eye-bolts $(12.7 \mathrm{~mm}$ diameter, $25.4 \mathrm{~cm}$ long$)$ through the north crossbeam with tension set by compression springs (MU COMP, 0.243 in., Ace Wire Spring \& Form Co., McKees Rocks, Pa.) (fig. 2). The snow fence is attached

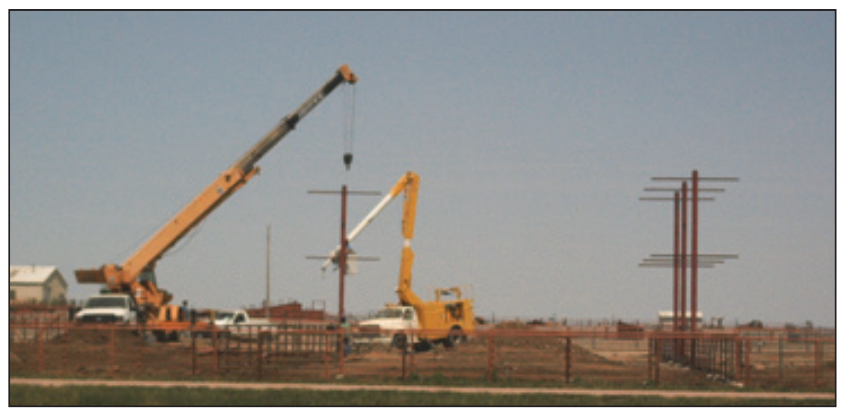

(a)

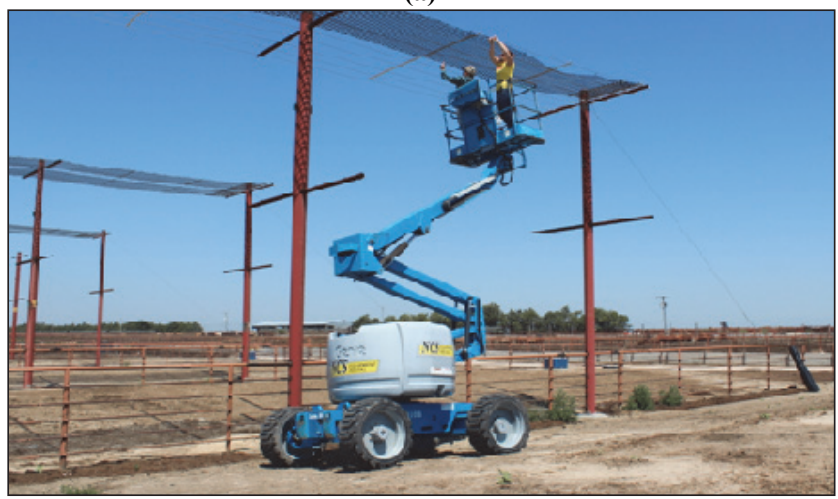

(b)

Figure 1. (a) Steel poles (10 $\mathrm{m}$ height, $0.203 \mathrm{~m}$ diameter) were fitted with two crossbeams separated by $3.0 \mathrm{~m}$, set in concrete $(2.3 \mathrm{~m}$ deep), and spaced $7.6 \mathrm{~m}$ apart on the fence line to support (b) attachment of the snow fence shade material in two tiers.

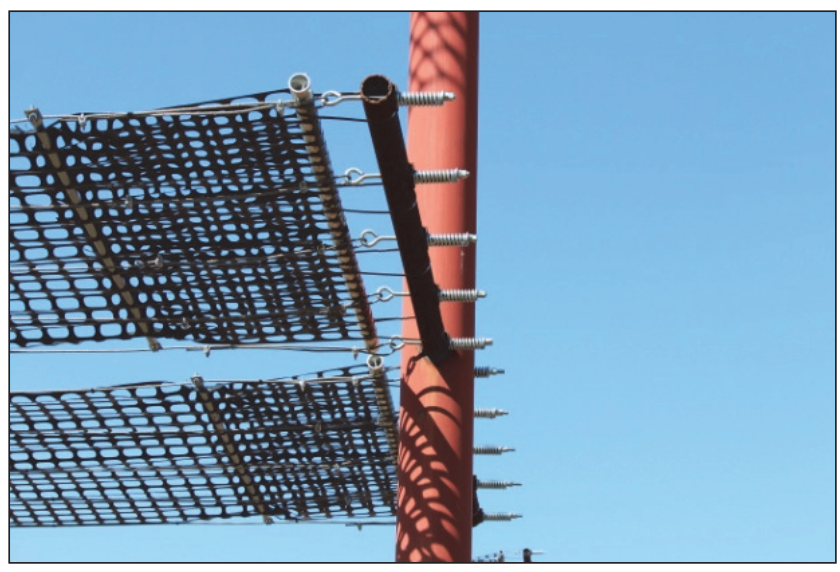

Figure 2. North crossbeam showing cable attachment with tensioning eye-bolt and spring assemblies. High-density, UV-stabilized snow fence material is strung between the support towers. 
to the five wire rope cables using UV-stabilized wire ties (Part No. MS90387-1, Panduit, Tinley Park, Ill., 203 mm long, $4.7 \mathrm{~mm}$ wide) at approximately $0.46 \mathrm{~m}$ intervals.

\section{EXPERIMENTAL DESIGN}

For this study, two rows (north and south) of ten pens each were used. The north row was without shade, and the south row had shade structures installed in the interior pen fence lines. Each pen measured $61.0 \mathrm{~m}$ long (N-S) by $30.5 \mathrm{~m}$ wide $(\mathrm{E}-\mathrm{W})$. The shade structures (15.2 m long) were installed midway in the N-S fence lines, but not in the end pen fence lines. For this study, all pens were stocked with 30 finishing cattle; however, measurements from the two end pens on the east and one end pen on the west were removed due to end effects and reduced shade space. Maintaining similar pens of cattle at both ends of the experimental pens helped to reduce pen-to-pen variation. The layout of the pens used in the analysis and all sampling locations are shown in figure 3 .

Weather conditions were measured every 15 min using a weather station (Vantage Pro 2, Davis Instruments, Hayward, Cal.). Information from the weather station included ambient temperature, humidity, wind speed, wind direction, and solar load. Solar radiation and black globe temperature (model 6450 solar radiation meter, Davis Instruments) were measured under the shade and outside of the shaded area in two pens. From the weather data, the index value of estimated respiration rate (EstRR) was calculated based on the following equation (Eigenberg et al., 2010):

EstRR $=5.4 T+0.58 R H-0.63 W S+0.024 R a d-110.9$

where

EstRR $=$ estimated respiration rate (breaths $\mathrm{min}^{-1}$ )

$T=$ ambient temperature $\left({ }^{\circ} \mathrm{C}\right)$
$R H=$ relative humidity $(\%)$

$W S=$ wind speed $\left(\mathrm{m} \mathrm{s}^{-1}\right)$

Rad $=$ solar radiation $\left(\mathrm{W} \mathrm{m}^{-2}\right)$.

Note that the calculated EstRR reported in this article is specifically for unshaded conditions. From Eigenberg et al. (2005), EstRR stress categories of normal (RR $\leq 85$ breaths $\left.\mathrm{min}^{-1}\right)$, alert $\left(85<\mathrm{RR} \leq 110\right.$ breaths $\left.\mathrm{min}^{-1}\right)$, danger $(110<$ $\mathrm{RR} \leq 133$ breaths $\mathrm{min}^{-1}$ ), and emergency $(\mathrm{RR}>133$ breaths $\min ^{-1}$ ) were used.

Individual weights of all cattle were taken once per month, including at the beginning of the study. Gains were calculated using linear regression. Daily feed supplied per pen was also recorded. A comparison of shaded versus nonshaded pens was completed for mid-May through mid-June (mild conditions) and for mid-June through mid-July (warm conditions). Average daily gain (ADG), feed intake, and feed to gain ratio $(\mathrm{F}: \mathrm{G})$ are reported.

Prior to beginning the study, the cattle were preconditioned to human observations of panting score (PS) and respiration rates (RR) for one week. During this period, two humans walked around the perimeter and through the pens for an hour twice each day to normalize the cattle to the movement of humans on foot. Observations were taken Monday through Friday at 9:30 and 13:30 for half the animals in each of six pens (three with and three without shade). The half of the pen sampled alternated from day to day, so over the course of six weeks approximately 30 observations were made for each animal ( 6 weeks $\times 2.5$ days per week $\times 2$ observations per day $=30$ observations per animal). Observations were taken using a group of two observers and two recorders. One observer/recorder pair worked in the shaded pens, while the second observer/recorder pair worked in the unshaded pens. Typically, the pairs alternated by day between shaded and unshaded pens. The recorder chose a lo-
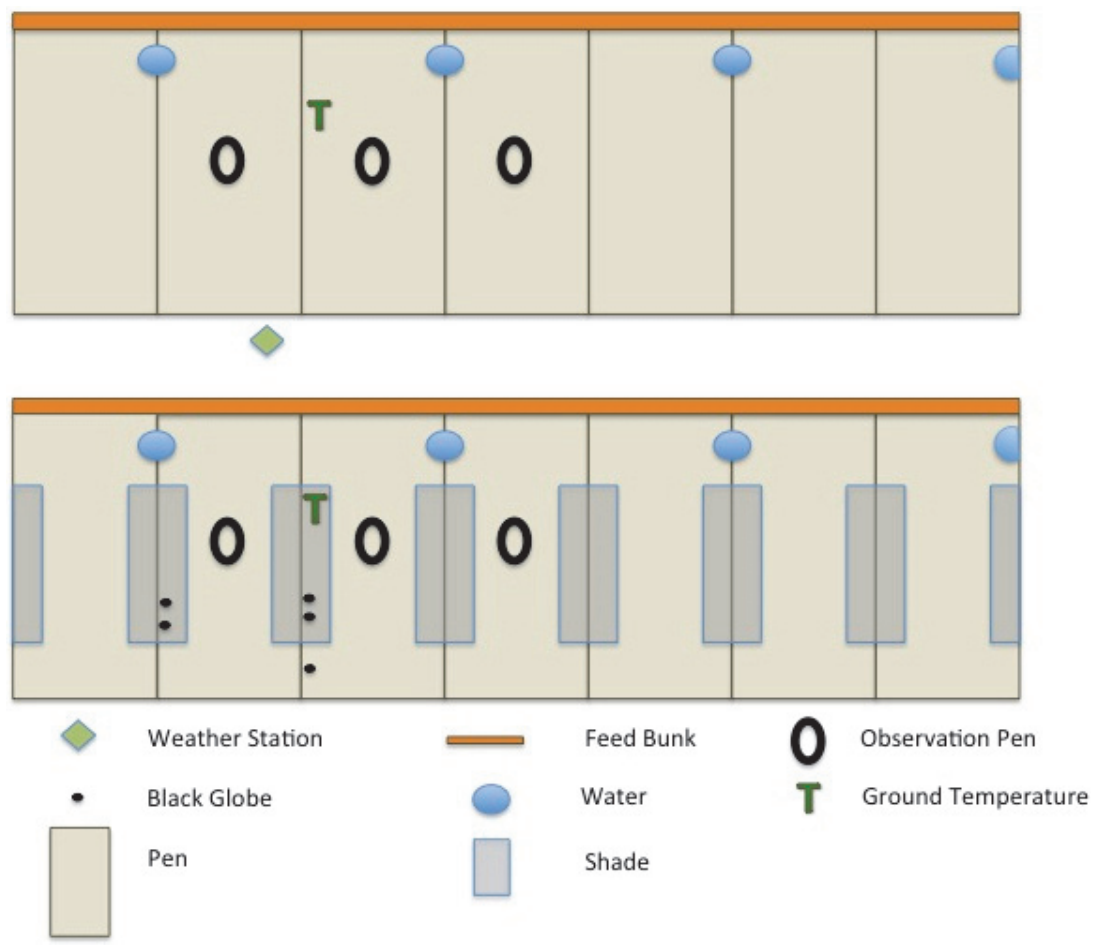

Figure 3. Drawing of the pens and specific sampling locations. North is to the top of the figure. 
cation near the edge of the pen and remained in one location. The recorders acted as observers for animals close to their location and recorded all data called out by the observers. The observers moved around within the pen to get information on the cattle, which included cattle that were difficult to observe within groups or near the edges of the pen. Data collected included identification number, PS, and RR. During daily observations, respiration rate was calculated by using a stopwatch to record the total time of ten flank movements. Panting scores were recorded using a 0 to 4.5 scale, with 0 indicating no panting and 4.5 indicating excessive drooling, mouth open, and tongue hanging out (Mader et al., 2006). Ground temperature was reported as the average of three spot checks made at the time of the pen observations using a handheld infrared thermometer (Raynger ST80 ProPlus, Raytek, Santa Cruz, Cal.) in both shaded and nonshaded conditions. The predictor of risk of heat stress (EstRR) was computed for each observation period in the morning $\left(\right.$ EstRR $\left._{\mathrm{AM}}\right)$ and afternoon (EstRR $\left.\mathrm{PM}_{\mathrm{PM}}\right)$.

In addition to daily observations, time-lapse cameras (TimeLapseCam, Wingscapes Alabaster, Ala.) were set up to take daily images every $5 \mathrm{~min}$. From these images, ten days of daily images at 8:00, 13:00, 17:00, and 20:00 were pulled for all pens. The images were analyzed to count the number of cattle under shade. Images with heavy cloud cover or rain were removed. Each time had at least seven good days in the final analysis.

\section{Statistical AnAlysis}

Environmental conditions of ground temperature and black globe temperature were analyzed to determine the effect of shade using t-tests computed with R software (R Core Team, 2012). Feed intake, ADG, and F:G were also analyzed using t-tests to determine if shade had an effect on these performance measures. Feed intake was measured at the pen level, and ADG was determined by weights taken at approximately monthly intervals. This resulted in daily feed intake values being repeated measures within the monthly intervals, and individual weights were repeated measures within the pen. Because warm conditions were experienced only in the final seven-week period, only data from that period were reported in this analysis. With all the repeated measures, there were only seven samples for the shaded and non-shaded groups, which caused SE to be high.

Effects of shade and color (independent of breed) on RR, PS, and ADG were analyzed in a four-trait mixed model using the ASreml statistical package (Gilmour et al., 2015). Respiration rates taken in the morning $\left(R_{A M}\right)$ were considered the first trait, and those taken in the afternoon $\left(R_{P M}\right)$ were the second trait. Panting scores taken in the morning $\left(\mathrm{PS}_{\mathrm{AM}}\right)$ were the third trait, and those taken in the afternoon (PS $\mathrm{PM}_{\mathrm{PM}}$ were the fourth trait. The first four traits were analyzed with a repeated records model in which the residual corresponded to a record of an animal on a given day. Average daily gain from mid-May to mid-June ( $\left.\mathrm{ADG}_{\text {Mild }}\right)$ was the fifth trait, and ADG from mid-June to mid-July ( $\left.\mathrm{ADG}_{\mathrm{Hot}}\right)$ was the sixth trait. Residuals for ADG traits corresponded to animals.

Fixed effects included sex (SEX: steer or heifer), sickness (SICK: none, preweaning, feedlot, or both), access to shade
(SHADE: none or shade), and predominant coat color (COLOR): white (14), gray (54), tan (39), brown (25), red (129), and black (126). Animals were mixtures of the following breeds: Angus, Red Angus, Hereford, Beefmaster, Shorthorn, Brangus, Brahman, Braunvieh, Santa Gertrudis, ChiAngus, Charolais, Gelbvieh, Limousin, Maine-Anjou, Salers, Simmental, MARC II, MARC III, Bonsmara, and Romosinuano. Contributions from commercial herds of Angus, Hereford, Charolais, Simmental, and Red Angus $\times$ Simmental cows were fit as separate genetic groups from the sires that were sampled from those breeds through artificial insemination. A set of covariates representing the breed percentages for each animal was computed and fitted as fixed effects to adjust for breed differences. These 25 covariates were collectively referred to as BREED. Results were considered significant at $\mathrm{p}=0.05$.

Ambient temperature was fit as a covariate in the model for RR and PS; however, when fit simultaneously with EstRR, it was not significant and was dropped from the final model.

Interactions of shade with color and breed were tested but dropped because they were not significant. Fixed linear and quadratic regressions of $\mathrm{RR}_{\mathrm{AM}}$ and $\mathrm{PS}_{\mathrm{AM}}\left(\mathrm{RR}_{\mathrm{PM}}\right.$ and $\left.\mathrm{PS}_{\mathrm{PM}}\right)$ on EstRR at the time of the respective observations were estimated. Interactions of linear EstRR with shade, breed, and color were tested and dropped if not significant. Only the interactions of EstRR with shade were retained in the final model.

Pen was fitted as a random effect (PEN). For the RR and PS traits, Julian date of observation was fitted as a random effect (DATE) with a first-order autoregressive covariance structure.

Two different random animal effects were fitted. The genetic effect (GENETIC) represented the additive genetic breeding value (the component of genetic merit transmitted from parent to offspring) of individual animals and in which the covariance structure among animals was described by a numerator relationship matrix, which described covariances due to genetic relationships among individuals. The permanent environmental effect (PE) was an animal-specific residual that accounted for non-genetic differences among individuals and was assumed to be identically and independently distributed across animals. The difference in covariance structures allows partitioning the variance between two different sources of variation.

To assess variability in the response of animals to heat stress, random regressions of each trait on the interactions of EstRR with GENETIC and PE were also fitted. The variances of theses interactions were estimated to be zero, so they were dropped from the final model.

Covariances among RR and PS traits for the observationlevel residuals (and separately for DATE) were modeled with $4 \times 5$ matrices constrained only to be symmetric and positive definite. For PEN and GENETIC, covariances among all six traits were estimated using a factor analytic structure with one factor for each covariance matrix. Because of the high correlations among traits for these random effects, more highly parameterized covariance models were not estimable. These covariance matrices were constrained 
to have non-negative covariances among the RR and PS traits. The covariances among PE (for the RR and PS traits) and observation-level residuals for the ADG traits were fit together with a $6 \times 6$ factor analytic structure with two factors.

The EstRR used for the interactions with animal were centered to a mean of zero and scaled to a variance of one so that the variance parameter estimates were on the same scale as the residual and animal variances. Observations of the PS and ADG traits were scaled by a factor of 100 to improve numerical stability for the analysis. Results were reported on the original scale.

\section{RESULTS AND DISCUSSION ENVIRONMENTAL RESPONSES}

During the six weeks monitored, average daily temperatures were moderate to warm. The average temperature was $24.8^{\circ} \mathrm{C}$. Typical weather for this period would be $23.1^{\circ} \mathrm{C}$ (Arguez et al., 2010). However, as figure 4 shows, there were no prolonged periods of very high temperatures.

Figure 5 further supports the suggestion that there were no extreme heat stress events during this six-week period.
On only one day was the $24 \mathrm{~h}$ estimated RR greater than 85 breaths $\mathrm{min}^{-1}$, which would cause to it move from "normal" into the "alert" category (Eigenberg et al., 2010). Using only weather data from the warmest hours of the day (11:00 to $18: 00), 20$ partial days are in the "alert" category and three partial days reach the "danger" category for that period. The relationships wherein these environmental conditions during the day resulted in afternoon estimated RRs in the "alert" and "danger" categories, while the whole-day estimated RR arrived at the "alert" category only once, indicated that the cattle were typically able to recover from any heat stress during cooler nights and early the next morning before temperatures started to climb again. Actual measured RRs tended to be higher than estimated RRs because actual measurements were taken at solar noon, while the estimated RRs included hours with potentially lower temperatures and less solar radiation.

The shade structures were effective at reducing solar radiation in the pens. Two measurements were made to evaluate the effectiveness of the shade in reducing solar load on the pens: ground surface temperature and black globe temperature. Ground temperatures showed a significant difference between shaded and unshaded areas. At 9:30 and 13:30,

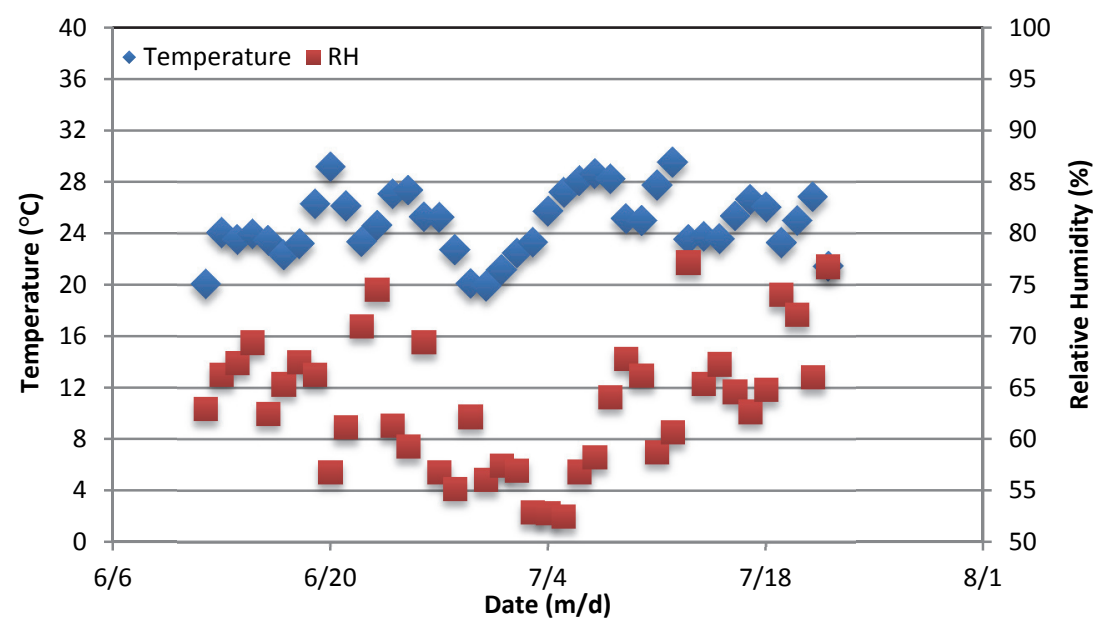

Figure 4. Average daily temperature and relative humidity (RH) in summer 2013.

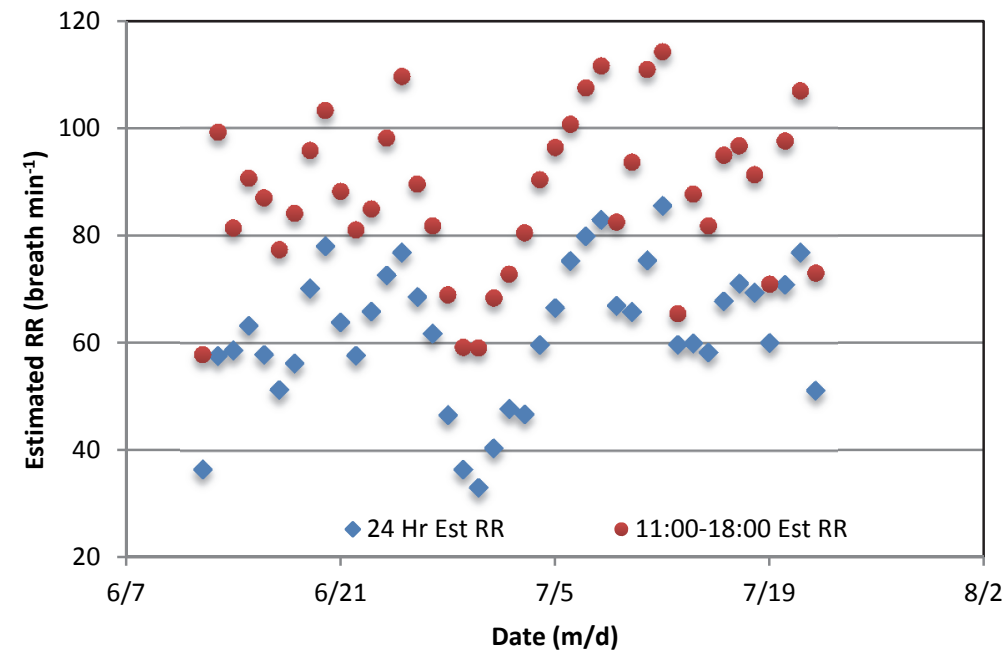

Figure 5. Average estimated respiration rates for daily and warm daylight hours in summer 2013. 
Table 1. Average ground temperatures reported for morning and midday observations. Values are means $( \pm \mathrm{SE})$.

\begin{tabular}{ccc}
\hline Time & Shade & No Shade \\
\hline $9: 30$ & $30.4^{\circ} \mathrm{C}\left( \pm 0.7^{\circ} \mathrm{C}\right)$ & $34.5^{\circ} \mathrm{C}\left( \pm 1.0^{\circ} \mathrm{C}\right)$ \\
$13: 30$ & $37.6^{\circ} \mathrm{C}\left( \pm 0.8^{\circ} \mathrm{C}\right)$ & $48.6^{\circ} \mathrm{C}\left( \pm 1.1^{\circ} \mathrm{C}\right)$ \\
\hline
\end{tabular}

the shade significantly $(\mathrm{p}=0.0015$ and $\mathrm{p}<0.0001$, respectively) reduced ground temperature, with ground temperature reduced by $4^{\circ} \mathrm{C}$ at $9: 30$ and by $11^{\circ} \mathrm{C}$ at $13: 30$ (table 1 ). Figure 6 shows that while the shade consistently provided a reduction in ground temperature, the amount of that reduction varied with solar radiation. On July 10, the minimum difference between the two ground temperatures was approximately $2^{\circ} \mathrm{C}$, while on June 26 , the maximum difference was almost $20^{\circ} \mathrm{C}$. The similar shaded and unshaded ground temperatures on July 10 were likely due to cloudy conditions during solar noon, which resulted in 30\% to $35 \%$ lower solar radiation measurements. Additionally, there was rainfall on July 9, which likely influenced ground temperatures in both pens.

Black globe temperature also showed significant $(\mathrm{p}=$ $0.0001)$ differences between measurements made under shade and without shade from 12:00 through 18:00. The shaded black globe temperatures were $2^{\circ} \mathrm{C}$ to $3^{\circ} \mathrm{C}$ lower than the unshaded temperatures (fig. 7). There were no significant differences between measurements made below one level of shade material and two levels of shade material; however, temperatures under two levels trended lower for all hours. While the second level of shade material may not have had as strong an impact in reducing black globe temperature, the second level of shade increased the area on the ground that was shaded when the sun was not directly overhead. As the angle of the sun shifted, both shade levels often acted as a single level of shade and projected shadows on different areas of the pen (fig. 8).

\section{Animal Shade Usage}

Time-lapse cameras were used to capture images of the pens, and images taken at 8:00, 13:00, 17:00, and 20:00 were pulled for analysis. The selected times were when feeding was not typically occurring and before daily observation oc- curred in some pens. The images were analyzed to determine the number of animals using the shade. Very few animals used the shade at either 8:00 or 20:00; however, more animals used the shade at 13:00 and 17:00 (fig. 9). This daily pattern of shade usage was expected. Each pen contained 30 cattle, and even in periods of increased shade usage, fewer than $1 / 3$ of the cattle used the shade on average during times of high solar radiation for all days selected for this analysis, even though there was ample room for all animals in the shade at all times of day. When the images were divided into periods above and below $27.5^{\circ} \mathrm{C}$, a difference in the average number of animals under shade was observed. For the 123 images with ambient temperatures below $27.5^{\circ} \mathrm{C}$, approximately $2.5( \pm 0.2 \mathrm{SE})$ animals were under shade, while the 16 images with ambient temperatures above $27.5^{\circ} \mathrm{C}$ had $8( \pm 1.2 \mathrm{SE})$ animals under shade. With such limited data for high temperatures, it is difficult to develop strong conclusions, but this certainly indicates more shade usage at higher temperatures.

\section{Efficiency Responses at the Pen Level}

Cattle performance measures included average daily gain (ADG) approximated from monthly weights with each animal measured individually, daily feed intake (FI) measured at pen level, and feed to gain ratio (F:G). Table 2 summarizes the performance with and without shade. Overall, none of the performance measures were significantly influenced by shade; however, ADG and F:G both showed nominally better results with the shade.

\section{Average Daily Gain Responses}

Steers gained $0.26 \pm 0.07 \mathrm{~kg} \mathrm{~d}^{-1}$ faster $(\mathrm{p}<0.004)$ than heifers during the early period and $0.16 \pm 0.06 \mathrm{~kg} \mathrm{~d}^{-1}$ faster $(\mathrm{p}=0.016)$ during the hotter period. SHADE, SICK, COLOR, BREED, SHADE $\times$ COLOR, and SHADE $\times$ BREED did not significantly $(\mathrm{p}>0.05)$ affect ADG during either period over which ADG was measured. The short periods between weights likely produced too much measurement error (resulting in residual standard deviations of about $0.3 \mathrm{~kg} \mathrm{~d}^{-1}$ ) to detect any but the largest differences in ADG.

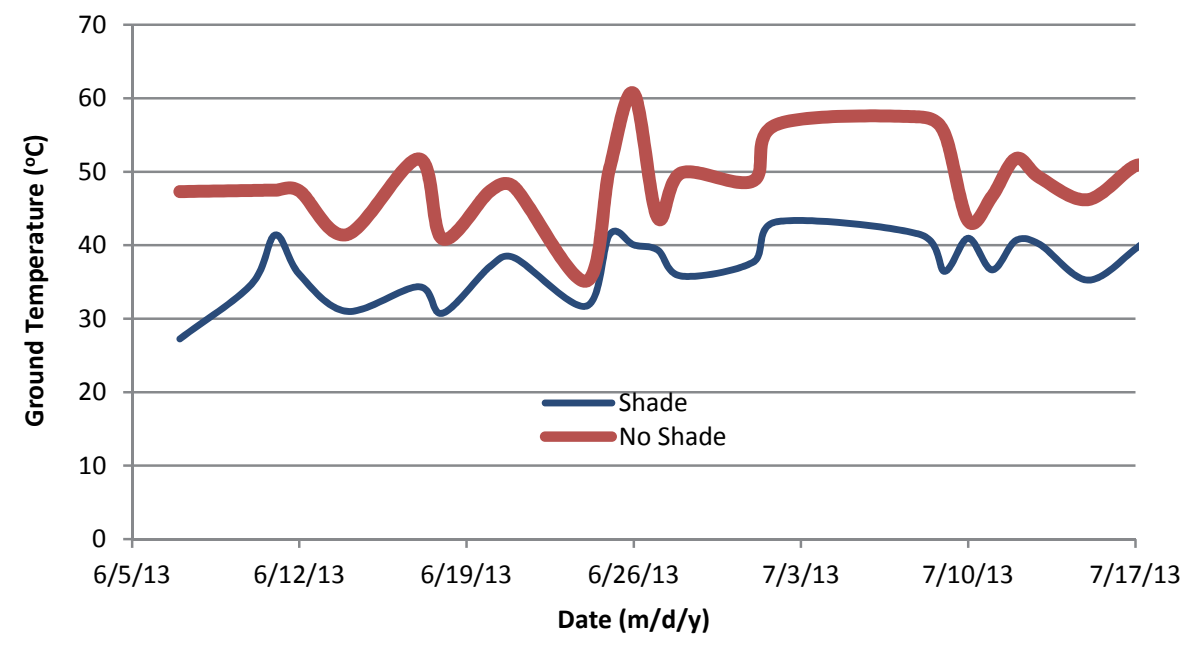

Figure 6. Smoothed lines showing the daily ground temperature measured slightly after solar noon (1:30 p.m. CDT) with shade reducing solar radiation and with no shade. 


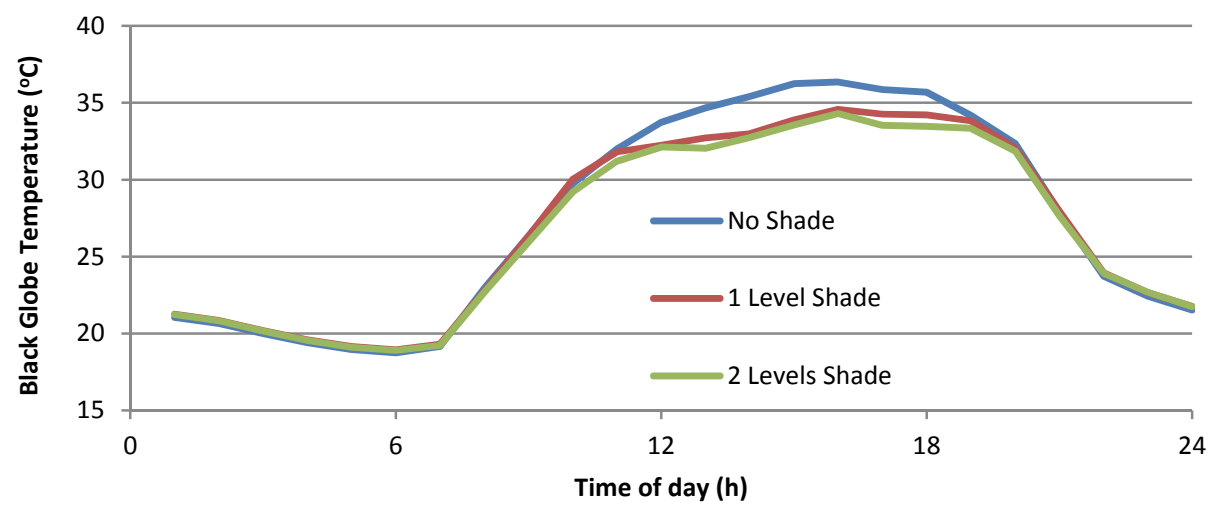

(a)

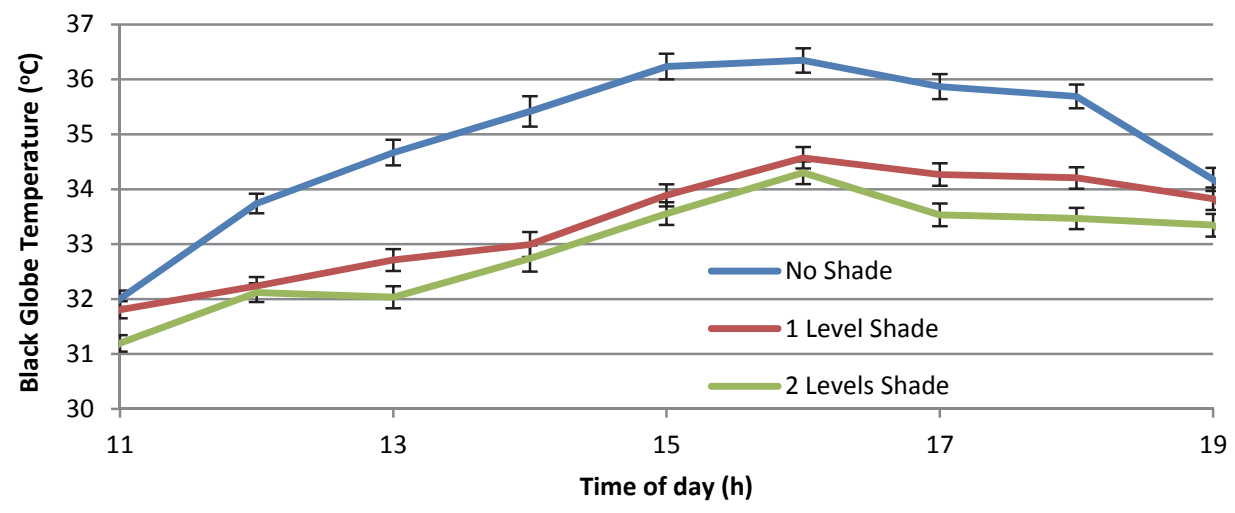

(b)

Figure 7. Average daily trend in black globe temperature from early June through mid-July 2013 for (a) entire 24 h period and (b) 8 h during which shade provided significant reduction in black globe temperature. Error bars in the bottom graph show \pm 1 SE for each hourly mean.

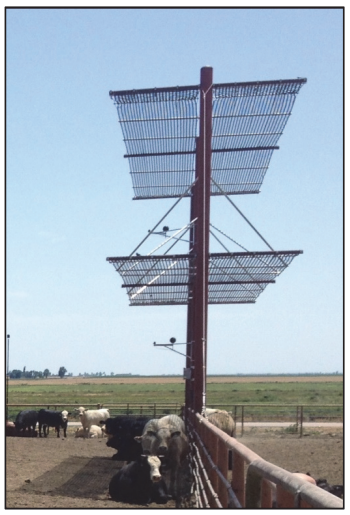

(a)

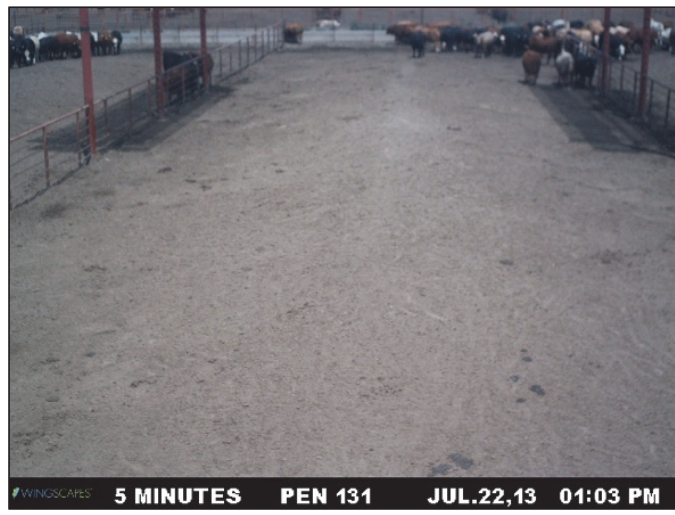

(b)

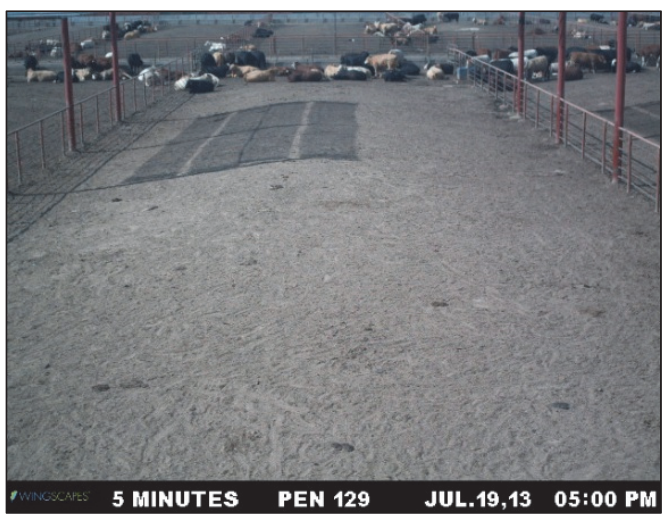

(c)

Figure 8. (a) Positions of the black globes and (b) shade acting as a double layer creating less shaded area but potentially greater solar reduction and (c) shade acting as a single layer with greater coverage area but potentially less solar reduction.

Furthermore, the cooler than typical temperatures, even during the hottest part of the feeding period, likely masked the effects of shade and its interaction with coat color. Significant differences in ADG among breeds are routinely found when larger numbers of animals per breed are measured over longer periods in the same facility without shade (e.g., Casas et al., 2010).

\section{Respiration Rates and Panting Score Responses}

While the performance of the cattle showed no significant differences, daily observations of RR and PS indicated that the shade was effective. Morning observations of RR and PS were included in the multiple trait model primarily to reduce noise from the afternoon observations through the correlations among the traits. The afternoon traits were obviously more likely to reflect actual heat stress. Nonetheless, $\mathrm{PS}_{\mathrm{AM}}$ was lower $(p=0.005)$ for cattle with shade than for cattle without shade. All four RR and PS traits increased with EstRR at an increasing rate (fig. 10).

Significance levels of fixed effects are presented in table 3. On average, cattle with shade had 6.3 breaths $\mathrm{min}^{-1}$ lower $\operatorname{RR}_{P M}(\mathrm{p}<0.001)$ and 0.25 lower $\mathrm{PS}_{\mathrm{PM}}(\mathrm{p}<0.001)$ than cattle without shade. For $\mathrm{RR}_{\mathrm{PM}}, \mathrm{PS}_{\mathrm{AM}}$, and $\mathrm{PS}_{\mathrm{PM}}$, the differences due to shade increased with heat stress, as meas- 


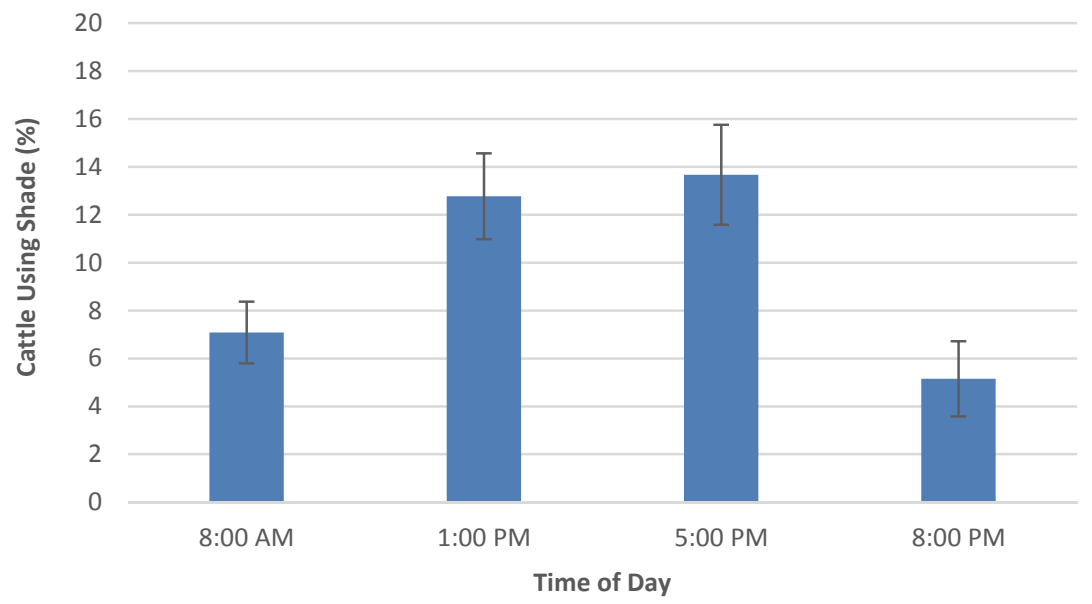

Figure 9. Average daily shade usage at four times of day during summer 2013. Error bars indicate $\pm 1 \mathrm{SE}$.

Table 2. Animal performance for the final $\mathbf{3 5}$ days in the feedlot, including average daily gain (ADG) approximated from monthly weights, daily feed intake (FI) measured at pen level, and feed to gain ratio (F:G) for animals with and without access to shade.

\begin{tabular}{ccccc}
\hline Pen Type & & $\begin{array}{c}\text { ADG } \\
\left(\mathrm{kg}_{\text {bw }}\right. \\
\left.\text { animal }^{-1} \mathrm{~d}^{-1}\right)\end{array}$ & $\begin{array}{c}\text { Daily FI } \\
\left(\mathrm{kg}_{\mathrm{dm}}\right. \\
\left.\mathrm{animal}^{-1} \mathrm{~d}^{-1}\right)\end{array}$ & $\begin{array}{c}\mathrm{F}: \mathrm{G} \\
\text { Ratio } \\
\left(\mathrm{kg}_{\mathrm{dm}} / \mathrm{kg}_{\mathrm{bw}}\right)\end{array}$ \\
\hline Shade & Mean & 0.95 & 16.27 & 10.7 \\
& $\mathrm{SE}$ & 0.04 & 0.20 & 0.38 \\
\hline No shade & Mean & 0.90 & 16.65 & 11.9 \\
& $\mathrm{SE}$ & 0.07 & 0.28 & 0.84 \\
\hline
\end{tabular}

ured by EstRR. At the mean EstRR ${ }_{P M}$ of 153.2 , cattle with shade had 6.3 breaths $\min ^{-1}$ lower RR $R_{P M}$ and 0.25 lower PS than cattle without shade. At an EstRR $R_{P M}$ of 175.0 (1.2 standard deviations above the mean), those differences increased to 11.3 breaths $\mathrm{min}^{-1}$ and 0.35 PS, respectively (fig. 10).

Breed was included in the model so that effects of coat color could be estimated independently of breed effects; otherwise, they would be heavily confounded, and it would not be possible to properly interpret estimates of coat color effects. The standard errors of breed effects were quite large, as the greatest contribution of any breed to the limited number of animals in the study was $11 \%$. Nonetheless, breed contributed significantly to explaining the variations in $\operatorname{RR}_{P M}(\mathrm{p}=0.002)$ and $\mathrm{PS}_{\mathrm{PM}}(\mathrm{p}=0.002)$.

Coat color had significant effects on $R_{P M}(p=0.04)$ and $\mathrm{PS}_{\mathrm{PM}}(\mathrm{p}=0.03)$. Adjusted means for coat color are reported in table 4. The coat color scores available for this project were extracted from color codes assigned by USMARC cattle operations staff for non-research purposes. It appears from the estimated effects that cattle that would genetically be considered light gray were coded as tan and that the cattle coded as gray were dark gray, but this could not be determined. In future studies of effects of coat color on heat tolerance, USMARC scientific staff will assign color scores with this specific purpose in mind.

All traits were lowly heritable. Heritability estimates were $0.07 \pm 0.08,0.03 \pm 0.05,0.005 \pm 0.012,0.0005 \pm 0.0047$, $0.17 \pm 0.11$, and $0.06 \pm 0.06$ for $\mathrm{RR}_{\mathrm{AM}}, \mathrm{RR}_{\mathrm{PM}}, \mathrm{PS}_{\mathrm{AM}}, \mathrm{PS}_{\mathrm{PM}}$, $\mathrm{ADG}_{\text {Mild }}$, and $\mathrm{ADG}_{\mathrm{Hot}}$, respectively. Heritabilities of RR and PS would likely have been higher in a hotter summer. Herit- ability of ADG decreases when measured over short periods of time (Retallick et al., 2017). The heritability of ADG computed over the combined periods was estimated to be $0.20 \pm 0.11$.

Variances, covariances, and correlations among traits for each random effect in the model are presented in table 5. Correlations among the RR and PS traits were very high for GENETIC, PE, and PEN, with most of those estimates on the boundary of the parameter space (constrained by software to be 0.999). Correlations between morning and afternoon traits were generally high. Analyzing them jointly allowed the morning traits to contribute to inferences about the afternoon traits. Correlations between the ADG traits and the measures of heat stress were generally low; analyzing them jointly probably contributed little relative to analyzing them separately.

The first-order autoregression on date of observation accounted for a sizeable fraction of the total variation for each of the RR and PS traits. The autocorrelation parameter was estimated to be 0.45 ; it represented the correlation between the effect of one day and the effect of the next day on the same trait. This term in the model was intended to account for the hypothesis that heat stress was not just a function of current temperature and humidity, but instead a function of heat load accumulated over several days. The estimated autocorrelation and correlations among traits for this term are supportive of this hypothesis.

\section{CONCLUSION}

In conclusion, the shade structure was successful in reducing solar load, as indicated by reduced ground and black globe temperatures. This reduced solar load also led to lower respiration rates $(\mathrm{p}<0.001)$ and panting scores $(\mathrm{p}<0.001)$ in the afternoons. While performance measures were nominally improved with shade, there were no significant differences in average daily gain, feed intake, and feed to gain ratio. The advantages of shade for respiration rate and panting score increased with heat stress, as measured by estimated RR. Significant differences were found among breed and color. 


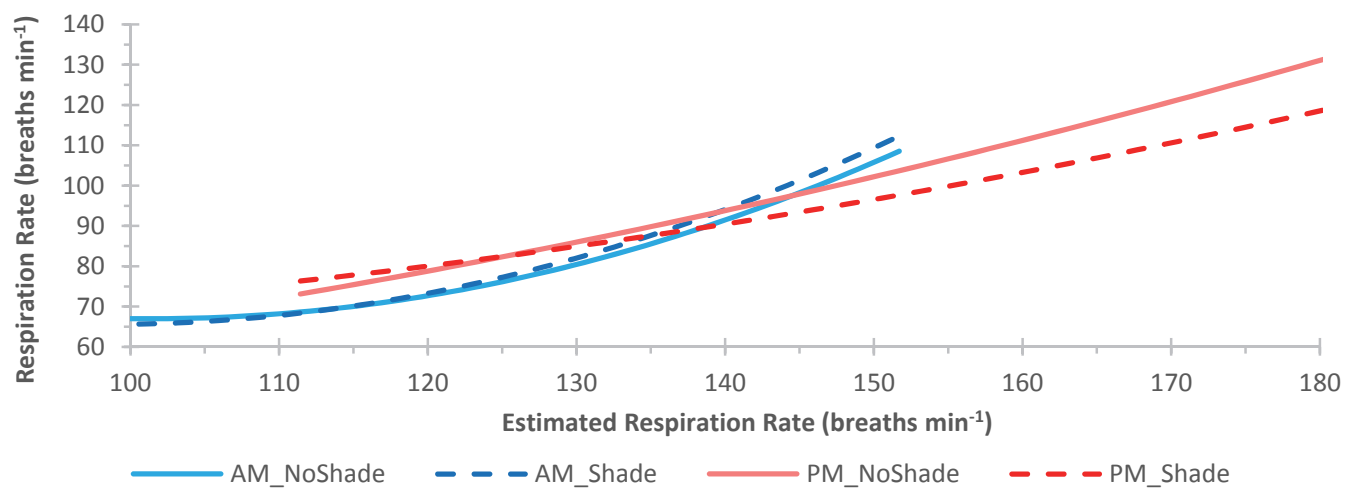

(a)

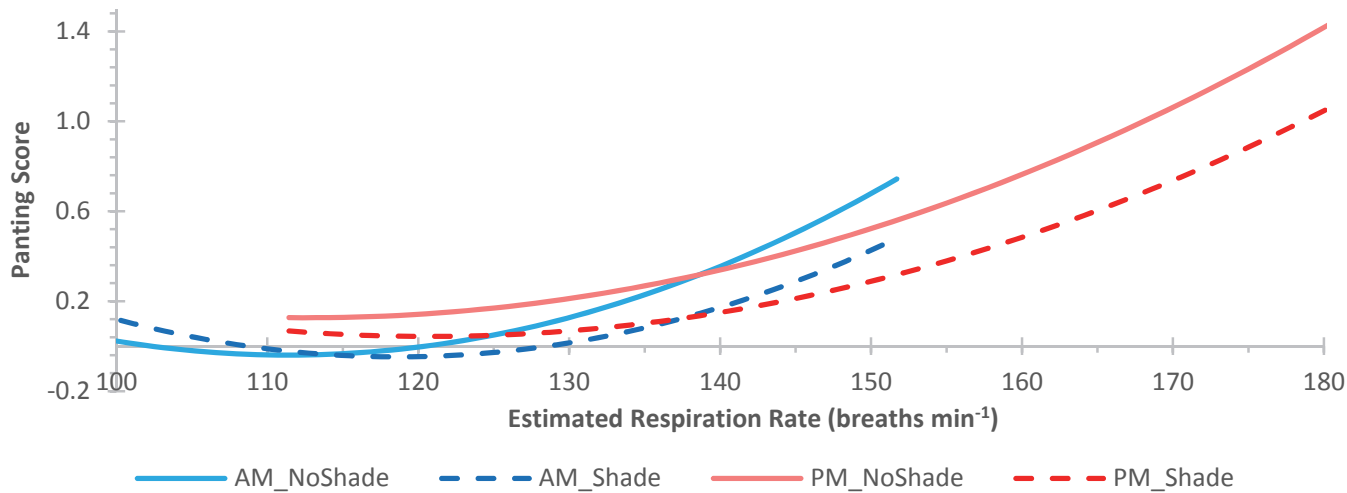

(b)

Figure 10. Adjusted means for (a) respiration rate and (b) panting score as functions of estimated respiration rate at the time of observation. Shade had a greater impact on reducing heat stress as estimated respiration rate increased. 
Table 3. Incremental Wald F-statistics and significance levels of fixed effects in the multiple-trait mixed model.

\begin{tabular}{|c|c|c|c|c|c|}
\hline Source & Trait & $\begin{array}{c}\text { Numerator } \\
\text { DF }\end{array}$ & $\begin{array}{c}\text { Denominator } \\
\text { DF }\end{array}$ & $\mathrm{F}$ & $\begin{array}{c}\mathrm{p} \\
\text { Value }\end{array}$ \\
\hline \multirow[t]{6}{*}{ SEX } & $\mathrm{RR}_{\mathrm{AM}}$ & 1 & 134.0 & 2.2 & 0.141 \\
\hline & $\mathrm{RR}_{\mathrm{PM}}$ & 1 & 132.3 & 0.3 & 0.560 \\
\hline & $\mathrm{PS}_{\mathrm{AM}}$ & 1 & 17.4 & 2.6 & 0.124 \\
\hline & $\mathrm{PS}_{\mathrm{PM}}$ & 1 & 94.3 & 0.3 & 0.588 \\
\hline & $\mathrm{ADG}_{\text {Mild }}$ & 1 & 11.0 & 12.7 & 0.004 \\
\hline & $\mathrm{ADG}_{\mathrm{Hot}}$ & 1 & 10.5 & 8.1 & 0.016 \\
\hline \multirow[t]{6}{*}{ SICK } & $\mathrm{RR}_{\mathrm{AM}}$ & 3 & 134.0 & 0.2 & 0.869 \\
\hline & $\mathrm{RR}_{\mathrm{PM}}$ & 3 & 134.8 & 0.3 & 0.818 \\
\hline & $\mathrm{PS}_{\mathrm{AM}}$ & 3 & 136.2 & 0.7 & 0.581 \\
\hline & $\mathrm{PS}_{\mathrm{PM}}$ & 3 & 147.9 & 1.9 & 0.138 \\
\hline & $\mathrm{ADG}_{\text {Mild }}$ & 3 & 344.9 & 1.1 & 0.344 \\
\hline & $\mathrm{ADG}_{\mathrm{Hot}}$ & 3 & 346.9 & 2.2 & 0.085 \\
\hline \multirow[t]{6}{*}{ SHADE } & $\mathrm{RR}_{\mathrm{AM}}$ & 1 & 133.3 & 0.7 & 0.395 \\
\hline & $\mathrm{RR}_{\mathrm{PM}}$ & 1 & 132.3 & 14.2 & $<0.001$ \\
\hline & $\mathrm{PS}_{\mathrm{AM}}$ & 1 & 14.2 & 10.8 & 0.005 \\
\hline & $\mathrm{PS}_{\mathrm{PM}}$ & 1 & 83.8 & 35.2 & $<0.001$ \\
\hline & $\mathrm{ADG}_{\text {Mild }}$ & 1 & 10.8 & 0.6 & 0.445 \\
\hline & $\mathrm{ADG}_{\mathrm{Hot}}$ & 1 & 10.3 & 0.0 & 0.862 \\
\hline \multirow[t]{6}{*}{ COLOR } & $\mathrm{RR}_{\mathrm{AM}}$ & 5 & 133.2 & 1.5 & 0.193 \\
\hline & $\mathrm{RR}_{\mathrm{PM}}$ & 5 & 133.3 & 2.4 & 0.039 \\
\hline & $\mathrm{PS}_{\mathrm{AM}}$ & 5 & 135.7 & 0.5 & 0.801 \\
\hline & $\mathrm{PS}_{\mathrm{PM}}$ & 5 & 144.5 & 2.6 & 0.026 \\
\hline & $\mathrm{ADG}_{\text {Mild }}$ & 5 & 317.7 & 0.4 & 0.862 \\
\hline & $\mathrm{ADG}_{\mathrm{Hot}}$ & 5 & 330.9 & 0.6 & 0.731 \\
\hline \multirow[t]{6}{*}{ BREED } & $\mathrm{RR}_{\mathrm{AM}}$ & 23 & 133.6 & 1.6 & 0.062 \\
\hline & $\mathrm{RR}_{\mathrm{PM}}$ & 23 & 133.2 & 2.5 & $<0.001$ \\
\hline & $\mathrm{PS}_{\mathrm{AM}}$ & 23 & 136.3 & 1.3 & 0.203 \\
\hline & $\mathrm{PS}_{\mathrm{PM}}$ & 23 & 137.4 & 2.4 & 0.001 \\
\hline & $\mathrm{ADG}_{\text {Mild }}$ & 23 & 243.5 & 1.0 & 0.425 \\
\hline & $\mathrm{ADG}_{\mathrm{Hot}}$ & 23 & 283.5 & 0.7 & 0.857 \\
\hline EstRR $_{\mathrm{AM}}$ & $\mathrm{RR}_{\mathrm{AM}}$ & 1 & 26.0 & 47.2 & $<0.001$ \\
\hline EstRR $_{P M}$ & $\mathrm{RR}_{\mathrm{PM}}$ & 1 & 27.8 & 32.0 & $<0.001$ \\
\hline EstRR $_{\mathrm{AM}}$ & $\mathrm{PS}_{\mathrm{AM}}$ & 1 & 18.8 & 17.9 & $<0.001$ \\
\hline EstRR $_{P M}$ & $\mathrm{PS}_{\mathrm{PM}}$ & 1 & 29.2 & 20.9 & $<0.001$ \\
\hline$\left(\text { EstRR }_{\mathrm{AM}}\right)^{2}$ & $\mathrm{RR}_{\mathrm{AM}}$ & 1 & 24.1 & 6.3 & 0.019 \\
\hline$\left(\text { EstRR }_{\mathrm{PM}}\right)^{2}$ & $\mathrm{RR}_{\mathrm{PM}}$ & 1 & 26.7 & 0.3 & 0.611 \\
\hline$\left(\text { EstRR }_{\mathrm{AM}}\right)^{2}$ & $\mathrm{PS}_{\mathrm{AM}}$ & 1 & 22.8 & 14.1 & 0.001 \\
\hline$\left(\text { EstRR }_{P M}\right)^{2}$ & $\mathrm{PS}_{\mathrm{PM}}$ & 1 & 28.6 & 2.3 & 0.137 \\
\hline $\begin{array}{l}\text { Shade } \times \\
\text { EstRR }_{\mathrm{AM}}\end{array}$ & $\mathrm{RR}_{\mathrm{AM}}$ & 1 & 1829.3 & 4.4 & 0.037 \\
\hline $\begin{array}{l}\text { Shade } \times \\
\text { EstRR }_{P M}\end{array}$ & $\mathrm{RR}_{\mathrm{PM}}$ & 1 & 2085.7 & 29.3 & $<0.001$ \\
\hline $\begin{array}{l}\text { Shade } \times \\
\text { EstRR }_{\mathrm{AM}}\end{array}$ & $\mathrm{PS}_{\mathrm{AM}}$ & 1 & 1812.3 & 32.4 & $<0.001$ \\
\hline $\begin{array}{l}\text { Shade } \times \\
\text { EstRR }_{P M}\end{array}$ & $\mathrm{PS}_{\mathrm{PM}}$ & 1 & 2073.3 & 10.1 & 0.002 \\
\hline
\end{tabular}

\section{ACKNOWLEDGEMENTS}

Special thanks to Dale Janssen, John Holman, Stephanie Schuler, and Elaine VenJohn who assisted with sampling installations, observations, and recording of all data, as well the farm crew who provided care for the animals and assisted with data collection.

\section{REFERENCES}

Arguez, A., Durre, I., Applequist, S., Squires, M., Vose, R., Yin, X., \& Bilotta, R. (2010). NOAA's U.S. climate normals (19812010). Clay Center, NE: NOAA National Centers for Environmental Information. https://doi.org/10.7289/V5PN93JP

Blackshaw, J. K., \& Blackshaw, A. W. (1994). Heat stress in cattle and the effect of shade on production and behaviour: A review. Australian J. Exp. Agric., 34(2), 285-295. https://doi.org/10.1071/EA9940285

Bond, T. E., Kelly, C. F., Morrison, S. R., \& Pereira, N. (1967).
Table 4. Adjusted means for respiration rate and panting score in morning and afternoon for each coat color of cattle.

\begin{tabular}{cccccc}
\hline & \multicolumn{2}{c}{ Respiration Rate } & & \multicolumn{2}{c}{ Panting Score } \\
\cline { 2 - 3 } \cline { 5 - 6 } Color & $\begin{array}{c}\text { Morning } \\
(\mathrm{p}<0.18)\end{array}$ & $\begin{array}{c}\text { Afternoon } \\
(\mathrm{p}<0.037)\end{array}$ & & $\begin{array}{c}\text { Morning } \\
(\mathrm{p}<0.842)\end{array}$ & $\begin{array}{c}\text { Afternoon } \\
(\mathrm{p}<0.030)\end{array}$ \\
\hline White & $73.3 \pm 6.3$ & $96.2 \pm 7.6$ & & $0.010 \pm 0.099$ & $0.300 \pm 0.208$ \\
Gray & $82.5 \pm 3.9$ & $108.2 \pm 5.4$ & & $0.053 \pm 0.065$ & $0.620 \pm 0.159$ \\
Tan & $74.7 \pm 4.2$ & $98.0 \pm 5.7$ & & $0.014 \pm 0.068$ & $0.397 \pm 0.165$ \\
Brown & $81.7 \pm 4.8$ & $105.3 \pm 6.1$ & & $0.045 \pm 0.076$ & $0.593 \pm 0.175$ \\
Red & $78.7 \pm 3.9$ & $100.3 \pm 5.4$ & & $0.021 \pm 0.063$ & $0.410 \pm 0.158$ \\
Black & $81.2 \pm 3.9$ & $104.5 \pm 5.4$ & & $0.067 \pm 0.064$ & $0.527 \pm 0.158$ \\
\hline
\end{tabular}

Table 5. Variance component estimates. Covariances are left of the diagonals, variances are on the diagonals, and correlations are right of the diagonals. The panting score and average daily gain traits are scaled by 100 to make presentation more consistent.

\begin{tabular}{|c|c|c|c|c|c|c|}
\hline & $\mathrm{RR}_{\mathrm{AM}}$ & $\mathrm{RR}_{\mathrm{PM}}$ & $\begin{array}{l}\mathrm{PS}_{\mathrm{AM}} \\
\times 100\end{array}$ & $\begin{array}{l}\mathrm{PS}_{\mathrm{PM}} \\
\times 100\end{array}$ & $\begin{array}{c}\mathrm{ADG}_{\text {Mild }} \\
\times 100\end{array}$ & $\begin{array}{c}\mathrm{ADG}_{\mathrm{Hot}} \\
\times 100\end{array}$ \\
\hline \multicolumn{7}{|c|}{ Observation-level residual (RESIDUAL) } \\
\hline $\mathrm{RR}_{\mathrm{AM}}$ & 209.3 & 0.12 & 0.37 & 0.07 & - & - \\
\hline $\mathrm{RR}_{\mathrm{PM}}$ & 32.7 & 329.8 & 0.07 & 0.46 & - & - \\
\hline $\mathrm{PS}_{\mathrm{AM}} \times 100$ & 197.0 & 47.6 & 1375.0 & 0.05 & - & - \\
\hline $\mathrm{PS}_{\mathrm{PM}} \times 100$ & 65.8 & 506.7 & 114.4 & 3720.0 & - & - \\
\hline \multicolumn{7}{|l|}{ Pen (PEN) } \\
\hline $\mathrm{RR}_{\mathrm{AM}}$ & 0.0 & - & - & - & - & - \\
\hline $\mathrm{RR}_{\mathrm{PM}}$ & 0.0 & 0.0 & - & - & - & - \\
\hline $\mathrm{PS}_{\mathrm{AM}} \times 100$ & 0.0 & 0.0 & 5.0 & 1.00 & 0.38 & 1.00 \\
\hline $\mathrm{PS}_{\mathrm{PM}} \times 100$ & 0.0 & 0.0 & 2.4 & 1.2 & 0.38 & 1.00 \\
\hline $\mathrm{ADG}_{\text {Mild }} \times 100$ & 0.0 & 0.0 & 10.1 & 4.9 & 137.3 & 0.38 \\
\hline $\mathrm{ADG}_{\mathrm{Hot}} \times 100$ & 0.0 & 0.0 & 17.8 & 8.5 & 35.7 & 62.8 \\
\hline \multicolumn{7}{|c|}{ Additive genetics (GENETIC) } \\
\hline $\mathrm{RR}_{\mathrm{AM}}$ & 0.0 & 1.00 & 1.00 & 1.00 & 1.00 & 1.00 \\
\hline $\mathrm{RR}_{\mathrm{PM}}$ & 0.0 & 0.0 & 1.00 & 1.00 & 1.00 & 1.00 \\
\hline $\mathrm{PS}_{\mathrm{AM}} \times 100$ & 0.0 & 0.0 & 0.0 & 1.00 & 1.00 & 1.00 \\
\hline $\mathrm{PS}_{\mathrm{PM}} \times 100$ & 0.0 & 0.0 & 0.0 & 63.1 & 1.00 & 1.00 \\
\hline $\mathrm{ADG}_{\text {Mild }} \times 100$ & 0.0 & 0.0 & 0.0 & 112.9 & 202.5 & 1.00 \\
\hline $\mathrm{ADG}_{\mathrm{Hot}} \times 100$ & 0.0 & 0.0 & 0.0 & 65.4 & 117.1 & 67.9 \\
\hline \multicolumn{7}{|c|}{ Animal-level residual (PE) } \\
\hline $\mathrm{RR}_{\mathrm{AM}}$ & 65.8 & 1.00 & 0.85 & 1.00 & -0.01 & -0.16 \\
\hline $\mathrm{RR}_{\mathrm{PM}}$ & 69.5 & 73.6 & 0.85 & 1.00 & -0.01 & -0.16 \\
\hline $\mathrm{PS}_{\mathrm{AM}} \times 100$ & 60.2 & 63.7 & 75.4 & 0.85 & -0.01 & -0.13 \\
\hline $\mathrm{PS}_{\mathrm{PM}} \times 100$ & 129.7 & 137.2 & 118.9 & 256.5 & -0.01 & -0.16 \\
\hline $\mathrm{ADG}_{\text {Mild }} \times 100$ & -1.5 & -1.6 & -1.4 & -3.1 & 826.7 & -0.16 \\
\hline $\mathrm{ADG}_{\mathrm{Hot}} \times 100$ & -39.7 & -42.0 & -36.4 & -78.4 & -145.6 & 981.7 \\
\hline \multicolumn{7}{|c|}{ First-order autoregression of observation date (DATE) } \\
\hline $\mathrm{RR}_{\mathrm{AM}}$ & 84.0 & 0.65 & 0.68 & 0.70 & - & - \\
\hline $\mathrm{RR}_{\mathrm{PM}}$ & 89.7 & 223.6 & 0.22 & 0.84 & - & - \\
\hline $\mathrm{PS}_{\mathrm{AM}} \times 100$ & 94.9 & 49.9 & 234.0 & 0.44 & - & - \\
\hline $\mathrm{PS}_{\mathrm{PM}} \times 100$ & 301.2 & 587.3 & 313.5 & 2191.0 & - & - \\
\hline
\end{tabular}

Solar, atmospheric, and terrestrial radiation received by shaded and unshaded animals. Trans ASAE, 10(5), 622-627.

Brown-Brandl, T. M., Eigenberg, R. A., \& Nienaber, J. A. (2013). Benefits of providing shade to feedlot cattle of different breeds. Trans. ASABE, 56(4), 1563-1570. http://dx.doi.org/10.13031/trans.56.9902

Casas, E., Thallman, R. M., Kuehn, L. A., \& Cundiff, L. V. (2010). Postweaning growth and carcass traits in crossbred cattle from Hereford, Angus, Brangus, Beefmaster, Bonsmara, and Romosinuano maternal grandsires. J. Animal Sci., 88(1), 102108. https://doi.org/10.2527/jas.2009-2271

Eigenberg, R. A., Brown-Brandl, T. M., \& Hayes, M. D. (2013). Shade structure design and evaluation. ASABE Paper No. 131618879. St. Joseph, MI: ASABE. https://doi.org/10.13031/aim.20131595866

Eigenberg, R. A., Brown-Brandl, T. M., \& Nienaber, J. A. (2010). Shade material evaluation using a cattle response model and meteorological instrumentation. Intl. J. Biometeorol., 54(6), 601607. https://doi.org/10.1007/s00484-010-0381-6 
Eigenberg, R. A., Brown-Brandl, T. M., Nienaber, J. A., \& Hahn, G. L. (2005). Dynamic response indicators of heat stress in shaded and non-shaded feedlot cattle: Part 2. Predictive relationships. Biosyst. Eng., 91(1), 111-118. https://doi.org/10.1016/j.biosystemseng.2005.02.001

Gaughan, J. B., Holt, S. M., Hahn, G. L., Mader, T. L., \& Eigenberg, R. (2000). Respiration rate: Is it a good measure of heat stress in cattle? Asian Australasian J. Animal Sci., 13(supp. C), 329-332.

Gaughan, J. B., Mader, T. L., Holt, S. M., \& Lisle, A. (2008). A new heat load index for feedlot cattle. J. Animal Sci., 86(1), 226234. https://doi.org/10.2527/jas.2007-0305

Gebremedhin, K. G., Hillman, P. E., Lee, C. N., Collier, R. J., Willard, S. T., Arthington, J. D., \& Brown-Brandl, T. M. (2008). Sweating rates of dairy cows and beef heifers in hot conditions. Trans. ASABE, 51(6), 2167-2178. https://doi.org/10.13031/2013.25397

Gilmour, A. R., Gogel, B. J., Cullis, B. R., Wellham, S. J., \& Thompson, R. (2015). ASreml User Guide, release 4.1. Hemel Hempstead, UK: VSNi International. Retrieved from http://www.vsni.co.uk/software/asreml/

Hahn, G. L., \& Mader, T. L. (1997). Heat waves in relation to thermoregulation, feeding behavior, and mortality of feedlot cattle. Proc. 5th Intl. Livestock Environ. Symp. (pp. 563-567). St. Joseph, MI: ASAE.

Hillman, P. E., Gebremedhin, K. G., Brown-Brandl, T. M., \& Lee, C. N. (2005). Thermal analysis and behavioral activity of heifers in shade or sunlight. Proc. 7th Intl. Livestock Environ. Symp. St. Joseph, MI: ASABE. https://doi.org/10.13031/2013.18360

Mader, T. L., Davis, M. S., \& Brown-Brandl, T. (2006).
Environmental factors influencing heat stress in feedlot cattle. $J$. Animal Sci., 84(3), 712-719. https://doi.org/10.2527/2006.843712x

Mitlöhner, F. M., Galyean, M. L., \& McGlone, J. J. (2002). Shade effects on performance, carcass traits, physiology, and behavior of heat-stressed feedlot heifers. J. Animal Sci., 80(8), 2043-2050. https://doi.org/10.2527/2002.8082043x

Mitlöhner, F. M., Morrow, J. L., Dailey, J. W., Wilson, S. C., Galyean, M. L., Miller, M. F., \& McGlone, J. J. (2001). Shade and water misting effects on behavior, physiology, performance, and carcass traits of heat-stressed feedlot cattle. J. Animal Sci., 79(9), 2327-2335. https://doi.org/10.2527/2001.7992327x

Parker, B. F. (1963). Heat transmission characteristics of sloped roofs exposed to solar radiation. Trans. ASAE, 8(1), 1-5.

R Core Team. (2012). R: A language and environment for statistical computing. Vienna, Austria: R Foundation for Statistical Computing. Retrieved from http://Www.R-project.org/.

Retallick, K. J., Bormann, J. M., Weaber, R. L., MacNeil, M. D., Bradford, H. L., Freetly, H. C., ... Kuehn, L. A. (2017). Genetic (co)variance and breed differences for feed intake and average daily gain to improve feed efficiency in growing cattle. $J$. Animal Sci. (in press).

Robertshaw, D. (1985). Heat loss of cattle. In M. K. Yousef (Ed.), Stress physiology in livestock (pp. 55-66). Boca Raton, FL: CRC Press.

Sullivan, M. L., Cawdell-Smith, A. J., Mader, T. L., \& Gaughan, J. B. (2011). Effect of shade area on performance and welfare of short-fed feedlot cattle. J. Animal Sci., 89(9), 2911-2925. https://doi.org/10.2527/jas.2010-3152 